\section{Using a Culturally Responsive Lens in the Revision of a Core Preparation Course}

\author{
AUTHORS \\ Kia R. Williams, \\ Margaret $P$. Weiss and \\ Pamela H. Baker \\ Journal of Special \\ Education Preparation \\ 1(2), 36-47 \\ (C) 2021 Williams, Weiss and Baker \\ Licensed with CC-BY-NC-ND 4.0 \\ License \\ DOI: 10.33043/JOSEP.1.2.36-47 \\ openjournals.bsu.edu/JOSEP
}

\title{
ABSTRACT
}

With increasing cultural diversity in schools and in special education, teachers must be prepared to meet the needs of students from diverse backgrounds. In addition to evidence-based practices, culturally sustaining pedagogy (CSP) is critical to helping students make meaning of their learning. Therefore, teacher preparation programs must be intentional and explicit in their instruction related to CSP for teacher candidates. We describe a replicable process of course review and revision for the inclusion of CSP with an example from a core course in a special education preservice teacher licensure program. The course, Intersectionality and Disability, is a course in a newly-implemented undergraduate licensure program.

\section{KEYWORDS}

\section{Culturally responsive teaching, culturally sustaining pedagogy, cur- riculum revision, teacher preparation}

$\mathbf{T}$ oday's schools and classrooms are increasingly diverse. According to the National Center for Education Statistics (NCES), in fall 2020, 50.7 million students were projected to attend public elementary, middle, and high schools in the United States. Of those, 23.4 million (approximately 46\%) were White students; 25.1 million (approximately 50\%) were Hispanic, Black, Asian, American Indian/Alaska Native, or Pacific Islander students; and 2.3 million (approximately 4\%) were students of two or more races (NCES, 2020). In special education, the demographics include a greater percentage of students from diverse backgrounds. For example, for the 2019-2020 school year, the percentage of students age 3-21 served under IDEA was: $15 \%$ white; $67 \%$ black, Hispanic, Asian, American Indian/Alaska Native, or Pacific Islander; and $15 \%$ two or more races (NCES, 2021; does not equal 100\%). Given these demographic factors, it is critical that teacher preparation programs are ready to prepare all teachers to work with students of color. As Billingsley et al. (2019) state, "Finally, it is important to emphasize that all teachers, including those of color, need opportunities to learn about effectively addressing the needs of a diverse student body" ( $p$. 208).

Meeting the needs of a diverse student body requires that teacher preparation programs not just assume candidates will "get it" as they learn about evidence-based practices but that preparation intentionally and explicitly addresses the need for teachers to understand how culture plays a role in the student experience and in the effective delivery of special education services (King $\&$ Butler, 2015). The term culture, as defined by sociologists, means "the languages, customs, beliefs, rules, arts, knowledge, and collective identities and memories developed by members of all social groups that make their social environments meaningful" (American Sociological Association, n.d.). Critical to this learning about culture and its impact is the development of intersectional competence and knowledge of culturally sustaining pedagogy. Intersectional competence "describes teachers' 
understanding of diversity and how students', families', and colleagues' multiple sociocultural markers [including disability] intersect in nuanced and complex ways" (Boveda \& Aronson, 2019 , p. 249). Important in this definition is that there are many intersections (e.g., disability, race, culture, gender) within individuals and there are many individuals that a teacher will encounter (e.g., students, families, colleagues).

Also important to intersectional competence is identifying and understanding one's own perceptions and biases. This helps a teacher create a welcoming, effective learning environment and may lead to better outcomes for the student (Pang et al., 2021).

Culturally sustaining pedagogy (CSP) builds upon the research and thinking of culturally relevant and culturally responsive pedagogy (Kelly et al., 2021). According to Paris (2012), who suggested the concept, CSP "requires that they [teachers] support young people in sustaining the cultural and linguistic competence of their communities while simultaneously offering access to dominant cultural competence" ( $p$. 95). The ideas of CSP, then, move away from deficit pedagogies or pedagogy that focuses on the dominant culture and language in an effort to "eradicate the linguistic, literate, and cultural practices many students of color brought from their homes and communities" (Paris, 2012, p. 93) and moves closer to including culture as a way to bring meaning to learning. This is not the "food and festivals" approach (King \& Butler, 2015, p. 47) to instruction but "the learning and relearning of information from multiple perspectives" (p. 47). According to Lubin et al. (2020), most teachers are not prepared to meet the needs of the culturally diverse student population. In order for teacher candidates to incorporate CSP into their future classrooms, they must learn to understand what it is, how their own beliefs influence their instruction, and how to approach learning about their students at the same time they learn about evidence-based practices and the teaching profession in their preparation programs.

While race and ethnicity are often the topic of discussion in culture, disability is an additional sociocultural marker that adds to a student's experience and understanding of themselves. Special education teacher preparation programs have the additional responsibility of including disability in the discussion of intersectionality and cultural competence. In fact, a review of the Council for Exceptional Children Initial Preparation Standards (CEC, 2021) reveals that the term "culturally responsive" or "culture" is included in five of the seven standards or key elements of standards. Therefore, it is critical that special education teacher preparation programs intentionally and explicitly address the dispositions and practices of CSP in coursework, along with the evidence-based practices that contribute to improved student outcomes. In order to do this, faculty must review and revise their courses using this lens and with these learning objectives in mind. We describe a replicable process of review and revision for special education, preservice teacher preparation courses using an example of a core course, Intersectionality and Disability, in a newly developed program. The review and revision were completed to address the dispositions and practices of CSP.

\section{Background Information about the Program}

Since the early 1990s, legislation in one mid-Atlantic state has required individuals who are interested in obtaining an initial teaching license to have a bachelor's degree in a field other than education. Only after obtaining the bachelor's degree could candidates pur- sue licensure either through a Masters of Teaching (an additional year of study after undergraduate work), a Masters of Education (additional 30 credits after bachelor's degree), or a certificate including required licensure courses and a petition from a school division as an alternative route now (Citation withheld to maintain anonymity). Unfortunately, with only these pathways, special education is listed as the top critical shortage area in the state and has been listed in the top three critical shortage areas for each of the last 20 years (name withheld to protect anonymity, 2020).

In 2016, the Task Force for Diversifying the State's Educator Pipeline and, in 2017, the Advisory Committee on Teacher Shortages recommended undergraduate licensure in order to encourage more diverse candidates to choose teaching. The then-Governor directed the Board of Education to "initiate emergency regulations creating an option for [the state's] public colleges and universities to offer an undergraduate program with a major in education" (2017). The General Assembly passed legislation to allow undergraduate degrees in education and, in fall of 2018, the next governor created an accelerated pace to launch these programs. Any undergraduate program submitted by April 1, 2019 to the State Council for Higher Education could expect approval (if guidelines were met) by May 2019 . The typical timeline for this process is three years.

A large public university within this state submitted and received approval for four programs for undergraduates in special education implemented in the fall 2019 semester. The programs were three initial licensure programs (K-12 students with disabilities who access the general curriculum, K-12 students with disabilities who access the adapted curriculum, PK-12 students who are blind/visually impaired) and one non-li- 


\section{TABLE 1: Core Courses for All Licensure Programs COURSE TITLE BRIEF DESCRIPTION}

\author{
Introduction to \\ special education \\ Classroom management and \\ positive behavior supports
}

Provides a survey of current knowledge on individuals with disabilities within the context of human growth and development across the life span.

\section{Technology integration}

Focuses on describing how school and classroom methods are used to establish effective learning environments for individuals with varying degrees of disabilities.
Reviews applications of recent educational and assistive technology for instruction.
Assessment

\begin{abstract}
Individualized behavior supports Assessment ties. academic behaviors of individuals with disabilities.
\end{abstract}

Offers knowledge and learning activities related to assessment of students with varying degrees of disabili-

\section{Consultation and collaboration}

Provides professionals in special education, general education, and related fields with knowledge and skills necessary for collaboration with a wide variety of stakeholders.

\section{Exploratory field experience}

Introduces students to the role of the special educator in academic and non-academic environments with students across disability areas.

\section{Transition and self-determination}

Examines relevant legislation and evidence-based practices related to person-centered transition planning for students with varying disabilities.
Intersectionality

Examines disability within a diversity and intersectionality context in K-12 schools. Analyzes how diversity and intersectionality informs the educational experience of individuals with and without disabilities to include race, gender, sexual orientation, socioeconomic status, and home/ language and culture. censure option. Though the licensure options were distinct, each program plan included nine core courses for all special education majors. The core courses are listed in Table 1. Initially, because of the rapid development phase, most of these core courses were the undergraduate equivalent of graduate level courses that were already in place, including similar learning objectives and assignments and no inclusion of CSP practices. However, the undergraduate programs included a field experience course and a course titled, Intersectionality and Disability, that had no graduate level equivalent.

After the first year of implementation of the new program, several faculty, including the second and third authors, undertook a program review process using the Collaboration for Effective Educator Development, Accountability, and Reform (CEEDAR) Center Roadmap for Educator Preparation Reform framework (CEEDAR, 2019) because instructors identified a mismatch between undergraduate student needs and course content. It is important to note that the 
demographic make-up of the faculty in this teacher preparation program at the time of development and review matched that of the national statistics: $71.6 \%$ of faculty were white and $80 \%$ female (Office of Institutional Assessment, 2021). While we carried out the review process in a stepwise fashion as described by CEEDAR, we also deviated slightly by identifying current doctoral students on Office of Special Education Programs (OSEP) Personnel Preparation grants at our university as stakeholders because of their positions as former special education teachers and future faculty in teacher preparation programs. As part of a course on Personnel Preparation in Special Education, doctoral students were given the option to conduct a course review of and suggest possible revisions to the new courses included in our undergraduate program (see Figure 1). After studying the research on CSP and special education teacher preparation in the course, the first author chose to review and revise the core course titled, Intersectionality and Disability. At the time of the review, the course had never been taught in the program.

\section{Positionality of Authors}

The first author identifies as an African American female doctoral student with interests in the use of interventions and assistive technology to positively impact the trajectory of academic success of students with disabilities, and students of color, and has interests in the self-efficacy of educators to effectively implement culturally responsive pedagogy. A dual-certified K-12 educator, she has experience as an elementary special education resource teacher and Autism program compliance coordinator in the second largest public school system in a mid-Atlantic state.

The second author identifies as a white female with more than 10 years of experience in teacher preparation at public

\section{FIGURE 1: Course Review Assignment Description}

\section{Option 1: Course Development}

Choose one course from any of the Mason special education undergraduate programs. You can use any of the posted syllabi as a starting point to guide your thinking; however, you will be given the standard course syllabus template to create your own course syllabus. The syllabus you create must include:

1. Your personal learning objectives (in addition to the programmatic ones)

2. Course schedule with topics and readings (textbook and/or journal articles)

3. Assignments (course performance evaluation) and grading guidelines for each

4. Course policies (including acceptance of late work, attendance/participation guidelines, communicating with you)

You must also create a lesson plan and supporting materials for three of the class meeting sessions (including the first session and any other two you choose).

institutions in the mid-Atlantic region. She has taught courses at the undergraduate, graduate, and doctoral level and conducted research in public schools at the middle and high school level. As a public-school teacher, she taught in rural and suburban schools. As both a special educator in K-12 public schools and as a learning specialist in student athlete academic support at a predominantly white institution, the majority of her students were students of color.

The third author also identifies as a white female with more than 15 years of experience in teacher preparation at predominantly white public institutions in the mid-Atlantic and midwest regions. She has taught all levels of students in higher education and, in K-12, was a special educator who specialized in working with students with emotional/ behavioral disorders.

\section{Conceptual Framework}

Critical to the development of teacher candidates is the idea that, before a teacher can use their knowledge of intersectionality of culture and disability in instruction, they must understand and recognize their own identity and individual and systemic biases. Once these individual characteristics are recognized and articulated in a supportive professional environment, a preparation program can then equip teacher candidates to develop practices and design instruction with an awareness and knowledge of racial and cultural issues to better meet the needs of their students (Pang et al., 2021).

To that end, our analysis of the Intersectionality and Disability course was informed by the conceptual framework of Chavez and Longerbeam (2016). Foundational to this work is the idea that both students (i.e., teacher candidates) and faculty bring their own cultural biases in how they learn, why they learn, how they interact with others, and who they believe is responsible for learning to their coursework. As in the discussion of culturally sustaining pedagogy for $\mathrm{K}-12$, instruction and coursework that is grounded in a cultural strengths-based approach and that offers a variety of ways to match beliefs about learning with activities will increase student learning (Chavez \& Longerbeam, 2016). In their model, Chavez and Longerbeam describe a continuum from individuated to integrated cultura frameworks for teaching and learning. Given that this replicable process was focused on a review of syllabus content and not classroom instruction, we targeted the continuum for the purpose of learning, ways of taking in and processing knowledge, interconnectedness of what is being 
learned, and responsibility for learning (Chavez \& Longerbeam, 2016, p. 8). This review process included analysis of the course objectives, learning outcomes, materials, and activities/assignments for evidence of a balance across the continuum of cultural norms and suggested revisions to each (Table 2 for a description of the continuum in these areas). In this review and revision, "balancing across cultural frameworks would mean that we engage the cultural strengths of every student in our teaching practices to enrich student learning overall" (Chavez \& Longerbeam, 2016, p. 9).

\section{Syllabus Review Process}

The first author conducted the syllabus review in several steps. First, the current syllabus was read through three times in order to become familiar with all components (the original and revised course syllabi can be found online in supplemental materials). Second, the author created a four-column chart with the headings of culturally relevant pedagogy, culturally responsive teaching self-efficacy, cultural sustaining pedagogy, and other course themes (e.g., racism/anti-racism, diversity). Third, the course catalog description, course overview, learner outcomes, course schedule, and course performance evaluation sections were copied from the original syllabus and pasted into the chart for analysis. Fourth, the first author reviewed each section for use of the terms "culturally relevant pedagogy," "culturally responsive teaching self-efficacy," and "cultural sustaining pedagogy."

Evidence of the use of these terms was included in the associated column within the chart (See Table 3). Finally, the second author read each of the identified sections to identify themes and evidence related to the cultural framework continuum (See Table 4).

Once evidence was collected from the syllabus components, gaps in the use of terms "culturally relevant pedagogy,"

TABLE 2: Cultural Framework Continuum in Teaching and Learning (selected items)

\begin{tabular}{|c|c|c|c|}
\hline Item & Individuated & Integrated & Course Items \\
\hline Purpose of learning & $\begin{array}{l}\text { Focus on individual } \\
\text { competence; } \\
\text { betterment of humanity }\end{array}$ & $\begin{array}{l}\text { Focus on collective } \\
\text { competence; } \\
\text { betterment of those } \\
\text { with whom connected }\end{array}$ & $\begin{array}{l}\text { Course title } \\
\text { Course description } \\
\text { Learning outcomes }\end{array}$ \\
\hline $\begin{array}{l}\text { Ways of taking in } \\
\text { and processing } \\
\text { knowledge }\end{array}$ & Mind is primary & $\begin{array}{l}\text { Mind, body, reflection, } \\
\text { emotions, relationships }\end{array}$ & $\begin{array}{l}\text { Course activities } \\
\text { Assignments }\end{array}$ \\
\hline $\begin{array}{l}\text { Interconnectedness } \\
\text { of what is being } \\
\text { learned }\end{array}$ & $\begin{array}{l}\text { Compartmentalized } \\
\text { and separate }\end{array}$ & $\begin{array}{l}\text { Contextualized and } \\
\text { connected }\end{array}$ & $\begin{array}{l}\text { Course activities } \\
\text { Assignments }\end{array}$ \\
\hline $\begin{array}{l}\text { Responsibility } \\
\text { for learning }\end{array}$ & Private, individual & Collective, shared & $\begin{array}{l}\text { Course activities } \\
\text { Assignments }\end{array}$ \\
\hline
\end{tabular}

*Adapted from Chavez \& Longerbeam (2016)

"culturally responsive teaching self-efficacy," and "cultural sustaining pedagogy" were identified and revisions to the course catalog description, course overview, and learner outcomes were made by the team. Critical themes that were not addressed in course schedule/readings or in course performance evaluations included racism/ anti-racism, diversity, identifying and disrupting white supremacy and anti-Blackness in Education and interlocking inequities (re)produced in education. Revisions to these sections were made by the authors to balance the material between individuated and integrated teaching and learning opportunities (Chavez \& Longerbeam, 2016) and to address these theme gaps.

\section{REVIEW RESULTS AND SUGGESTED REVISIONS}

Though additional revisions were made, we focus the results on the course title, description, overview, learning ac- tivities/assignments, and class schedule.

\section{Focusing the Course Title}

The course title provides teacher candidates with a first glance at the purpose and content of the course. The original name of the course was Intersectionality and Disability. Intersectionality, a term conceptualized by Kimberlé Williams Crenshaw (Haynes et al., 2020) more than 30 years ago, refers to the instances when race, class, gender, and other individual characteristics engage with one another and overlap. Disability is just one aspect of an individual. It is imperative that teacher candidates have a foundational understanding of how they conceptualize themselves and others, structure social relationships, and conceptualize knowledge before they can meet the needs of their students. Intersectionality is therefore a lens through which teachers develop their CSP. But the concept of CSP is not to stop with 
TABLE 3: Analysis of Syllabus for Elements of Cultural Relevant Pedagogy, Culturally Responsive Teaching and Cultural Sustaining Pedagogy

\begin{tabular}{|c|c|c|c|c|}
\hline $\begin{array}{l}\text { Culturally } \\
\text { relevant ped- } \\
\text { agogy }\end{array}$ & $\begin{array}{l}\text { Intersectionality framework to } \\
\text { IDENTIFY interconnectedness } \\
\text { of disability, race, class, } \\
\text { gender }\end{array}$ & $\begin{array}{l}\text { Use appropriate research } \\
\text { methods and resources } \\
\text { to APPLY social and } \\
\text { behavioral concepts/ } \\
\text { theories to students with } \\
\text { disabilities and supports } \\
\text { needed. }\end{array}$ & $\begin{array}{l}\text { DEVELOP critical } \\
\text { consciousness about } \\
\text { issues of race, class, } \\
\text { gender, culture, language } \\
\text { and educational equity/ } \\
\text { factors. }\end{array}$ & \\
\hline $\begin{array}{l}\text { Culturally } \\
\text { responsive } \\
\text { teaching }\end{array}$ & $\begin{array}{l}\text { EXPLAIN how K-12 student } \\
\text { learning and behavior are } \\
\text { impacted by SES, language/ } \\
\text { cultural background, race, } \\
\text { gender, disability, sexual } \\
\text { orientation, and trauma. }\end{array}$ & $\begin{array}{l}\text { UTILITIZE culturally } \\
\text { responsive practices with } \\
\text { families and community } \\
\text { members. }\end{array}$ & & \\
\hline $\begin{array}{l}\text { Self- } \\
\text { efficacy }\end{array}$ & $\begin{array}{l}\text { DEMONSTRATE culturally } \\
\text { sound and diversity informed } \\
\text { assessment practices for } \\
\text { learning and behavior. }\end{array}$ & $\begin{array}{l}\text { UNDERSTAND instruc- } \\
\text { tional practices sensitive to } \\
\text { culturally, linguistically, and } \\
\text { disability diverse students. }\end{array}$ & $\begin{array}{l}\text { IDENTIFY strengths and } \\
\text { challenges in one's own } \\
\text { cultural competency. }\end{array}$ & \\
\hline $\begin{array}{l}\text { Cultural } \\
\text { sustaining } \\
\text { pedagogy }\end{array}$ & $\begin{array}{l}\text { Restorative, evidence-based } \\
\text { practices in elementary and } \\
\text { secondary }\end{array}$ & & & \\
\hline $\begin{array}{l}\text { Observed } \\
\text { themes }\end{array}$ & $\begin{array}{l}\text { Disability as a diversity } \\
\text { construct }\end{array}$ & $\begin{array}{l}\text { Academic or behavioral } \\
\text { difficulties due to disability } \\
\text { or other diversity }\end{array}$ & $\begin{array}{l}\text { Social economic status } \\
\text { and impact of poverty on } \\
\text { student achievement }\end{array}$ & $\begin{array}{l}\text { Equity and the achievement gap } \\
\text { equity vs. equality }\end{array}$ \\
\hline
\end{tabular}

recognition. The next step is to use that lens to impact planning and instruction. To recognize this conceptual shift from a lens of awareness to taking action in impacting pedagogy precipitated a revision in the course name from Intersectionality and Disability to Culturally Responsive Pedagogy: Intersectionality in Teaching.

\section{The University Catalog Course Description and Course Overview}

The catalog description and course overview are part of the official university record of the focus of the course. The original catalog course description (below) tended toward an individuated description for the purpose of learning. The focus rests on "examining," "analyzing," and "assessing" components that were described as being external to the teacher candidate, without an examination of the teacher candidate's cultural competence and intersectional awareness.

\section{Examines disability within a} diversity and intersectionality context in K-12 schools. Analyzes how diversity and intersectionality informs the educational experience of individuals with and without disabilities to include race, gender, sexual orientation, socioeconomic status, and home/ language and culture. Assesses how cultural competency and intersectionality awareness on the part of educators enhance the school success of all students. Develops educator capacity to implement trauma-sensitive interventions in diverse settings for all students.

There was also no mention of CSP or how understanding intersectionality could impact planning and instruction. Revisions to the description included a focus on culturally relevant and/or sustaining pedagogy and culturally responsive teaching. It also included a component related to developing educator capacity of culturally sustaining instruc- 
TABLE 4: Analysis of Course Activities

\begin{tabular}{|c|c|c|c|}
\hline Item & Individuated & Integrated & Recommendation \\
\hline Intersectionality Project & $\begin{array}{l}\text { Individual, mind only, } \\
\text { compartmentalized } \\
\text { and disconnected from } \\
\text { experience }\end{array}$ & $\begin{array}{l}\text { Includes requirement to } \\
\text { articulate own background } \\
\text { understanding diversity }\end{array}$ & $\begin{array}{l}\text { Include experience of the classroom, small } \\
\text { group project, problem solve }\end{array}$ \\
\hline Media Analysis Paper & & $\begin{array}{l}\text { More integrated using } \\
\text { emotions/reflection on type of } \\
\text { media of interest; reflection, } \\
\text { connected with story }\end{array}$ & $\begin{array}{l}\text { Include variety of media in assignments; } \\
\text { have candidates experience/read about } \\
\text { perceptions of difference }\end{array}$ \\
\hline Blackboard Discussions & & $\begin{array}{l}\text { More integrated depending } \\
\text { on topics; social in that } \\
\text { responding to others; } \\
\text { connected to experience and } \\
\text { own ideas }\end{array}$ & $\begin{array}{l}\text { Focus on topics that will further efforts for } \\
\text { understanding and self-reflection }\end{array}$ \\
\hline Professionalism & & & Hard to determine \\
\hline Intersectionality Presentation & $\begin{array}{l}\text { Directions are limited; } \\
\text { focused on giving } \\
\text { information to others }\end{array}$ & Allows for choice in topic & \\
\hline
\end{tabular}

tional practices and understanding how they might impact students. See revised description below.

Examines the art and science of culturally sustaining pedagogy (CSP) within a diverse $K-12$ school context. Analyzes how a CSP, diversity, and disability lens informs the educational experience of individuals with and without disabilities. Assesses how cultural competency and intersectionality awareness on the part of educators enhance the school success of all students. Develops educator capacity to build culturally sustaining instructional practices into their disciplinary domain and maximize students learning opportunities.

The original course overview du- plicated the catalog description and, therefore, did not include the necessary attention to developing teacher candidate understanding of their own beliefs and biases. It also did not include ideas related to the impact that diversity has on instruction and student need or how the material would be connected or contextualized with student experiences. The revised description includes these factors:

\section{Culturally Sustaining Pedago-} gy: Intersectionality in Teaching examines how diversity impacts educational, relational and cultural responsiveness in $K-12$ education. This course supports students in reimagining schools with a focus on equity, deeper learning and shared leadership. Culturally Sustaining Pedagogy is designed to provide teacher candidates with an understanding of the sociocultural realities and histories of their students. This course highlights ways to negotiate the culture of the classroom with the identities of the students to foster a community of learning, uncover biases, design a diverse curriculum, and learn how systems in the classroom can support high expectations for all students. Course topics and themes covered in this course include race, culture, socioeconomic status, language, gender, sexual orientation, racism/anti-racism, equity, diversity, identifying and disrupting white supremacy and anti-Blackness in education and interlocking inequities (re)produced in education. 


\section{Learning Activities/ Assignments}

Critical to the course is how teacher candidates process and make sense of the material through assignments and activities. In the original syllabus, the majority of the assignments fell toward the individuated end of the continuum. For example, the Intersectionality Project required teacher candidates to find, summarize, and interpret research articles and "examine disability through an intersectionality lens" (p. 3). Though the project concluded with a reflection on the impact of the information on a candidate's ability to provide culturally sensitive and inclusive instruction, it did not ask the candidates to examine their own beliefs or to situate the research in their own experience. They were asked to share the project with their peers in a presentation. Collaborative learning was included in the major assignments through Discussion Board posts. Additionally, the course included a participation evaluation that emphasized professionalism and engagement but did not further delineate how these expectations were to be met.

In order to provide a balance along the continuum from individuated to integrated for the diversity of teacher candidates, several assignments were revised to include self-reflection and assessment as well as collaborative learning experiences. For example, the participation grade was broken into specific activities, including discussion board posts similar to those in the original syllabus and:

\section{a) Journal: Culturally Sustaining} Pedagogy Reflections. Each class will begin with a 5-to-10-minute response to a discussion prompt in the teacher candidate's online journal. The instructor will read each journal, ask questions, and encourage the candidate to think deeply about the topic.
FIGURE 2: CULTURALLY RESPONSIVE TEACHING SELF-EFFICACY INVENTORY*

\section{I am able to:}

1. Adapt instruction to meet the needs of my students

2. Obtain information about my students' academic strengths

3. Determine whether my students like to work alone or in groups

4. Determine whether my students feel comfortable competing with other students

5. Identify ways that the school culture (e.g., values, norms, practices) is different from my students' home culture

6. Implement strategies to minimize the effects of mismatch between students' home culture and school culture

7. Assess student learning using various types of assessments

8. Obtain information about my students' home live

9. Build a sense of trust in my students

10. Establish positive homeschool relationships

11. Use a variety of teaching methods

12. Develop a community of learners when my class consists of students from diverse backgrounds

13. Use my students' cultural background to help make learning meaningful
14. Use my students' prior knowledge to help them make sense of new information

15. Identify ways how students communicate at home may differ from the school norm

16. Obtain information about my students' cultural backgrounds

17. Teach students about their cultures' contributions to science

18. Greet English language learners with a phrase in their native language

19. Design a classroom environment that reflects a variety of cultures

20. Develop a personal relationship with my students

21. Obtain information about my students' academic weaknesses

22. Praise English language learners using a phrase in their native language

23. Identify ways that standardized tests may be biased towards linguistically diverse students

24. Communicate with parents regarding their child's educational progress

25. Structure parent-teacher conferences so that the meeting is not intimidating for parents

*Adapted from Siwatu (2007) 
b) Put In Practice (PIP): This is an opportunity for candidates to use what they have learned in class. Throughout the course, students will focus on specific methods of culturally sustaining pedagogy. Candidates will learn about practices that can be used in the K-12 classroom and then they will try out the new practice in a small group of peers. They will reflect upon the planning, success, and challenges faced during implementation.

Journal prompts occur on topics including the power of culture, historical oppression, social biases, and prejudice and bullying. The PIP activity follows readings and instruction in culturally responsive teaching principles and practices (e.g., reading Pang, 2018, chapter 8 and class session instruction).

Major course assignments were also redesigned to include (a) guided self-reflection, (b) making links between each candidate's experiences and beliefs and their instructional ideas, and (c) applying that knowledge to simulations of classrooms. For example, one assignment requires candidates to complete the Culturally Responsive Teaching Self-Efficacy Inventory (Siwatu, 2007; see Figure 2), and develop a personal growth plan for the semester. This is an individual assignment that allows candidates to reflect on their areas of strength and weakness related to culturally responsive teaching using a straightforward inventory. It also asks them to look to the course objectives, activities, and readings to consider how to use the content to meet their own goals for improvement. Candidates submit their plan to the instructor at the beginning of the semester, reflect upon it at multiple points throughout the course, and review their progress at the end of the semester.

Another example, the Capstone
Project, is a small group project (see Figure 3 for complete assignment). First, students choose a case study from a list. Next, the group watches a case study video and then determines how to learn more about the students in the case study. The group develops an action plan for using the data, creates a complete culturally relevant lesson plan for that classroom, and reflects on the experience. The small group work encourages dialogue and discussion related to real classrooms but in a way that is still "safe" for candidates. At each point in the project, the instructor provides feedback to the candidates before they continue.

\section{Class Schedule}

Finally, the original class schedule included only three references to "culturally responsive teaching" in topics throughout the semester. In addition, we found that textbook chapters (Pang, 2018) were included as specific readings through the course. Though article summaries were included as assignments, no article references were provided in the syllabus. Critical readings around the origin of culturally relevant and culturally sustaining pedagogy were added into the revision of the course to help candidates understand the conceptual foundation and ongoing research related to these topics. For example, seminal articles by Gloria Ladson-Billings (1995), Gay (2002), and Annamma et al. (2013) were added to the class schedule. Recent works that are practitioner-based, such as Collier et al. (2017) and Linan-Thompson et al. (2018), were also added.

Several class session topics in the original syllabus (e.g., equity vs. equality; educator implicit bias; and the impact of privilege, diversity and culture on education) remained in the revised course. However, to include additional themes and topics related to cultural- ly sustaining pedagogy, several class sessions were changed to topics such as (a) race: historical oppression; (b) social biases: discrimination based on religion, immigrant status, and exceptionalities; (c) prejudice and bullying; and (d) creating a culturally responsive community for learning. Class sessions on trauma in the school setting and the impact of trauma on learning and development were also removed from the schedule so as to not link intersectionality with trauma.

\section{Discussion and Implications}

Given the mismatch in K-12 student and teacher demographics and experiences, it is critically important to prepare teachers to provide instruction from a cultural strengths-based perspective (Pang et al., 2021). In order to do that, teacher candidates must be asked to examine their own beliefs, experiences, and biases as well as learn ways to know more about their students and plan instruction that meets the needs of their students. Teacher preparation programs must include coursework and field experiences that explicitly and intentionally guide candidates through this process.

According to Taylor and Hamdy (2013), adult learning occurs in an iterative process. Individuals experience dissonance in their understanding, reflect on it, develop new ideas, experiment with those ideas, and then, organize their new learning until they experience dissonance again. Kolb and Kolb (2009) add to this that the process occurs in a social environment. Critical to coursework in teacher preparation is experiencing this dissonance in ideas and beliefs with the opportunity to reflect on this dissonance and negotiate its outcome with others in the course. This process integrates with the learning framework continuum of Chavez and Longerbeam (2016) in that the 


\section{FIGURE 3: CAPSTONE ASSIGNMENT}

This is a small group project. Please make your own groups of 3-4 students.

The purpose of this project is two-fold: (1) to identify current classroom practices that are "getting in the way" of student learning and (2) to develop an action/improvement plan based on student surveys and classroom observations included in the case study video of your choice.

Your action/improvement plan will use critical pedagogy to implement culturally responsive teaching and increase student performance in your content area(s). Groups will access the referenced Cultural Competence article and synthesize the research from this semester that has a correlation to perceived implications for culturally responsive teaching, school leadership and student performance. Groups will give a live 10-minute presentation on their capstone project. (25 pts)

\section{Objectives}

1. To learn more about the cultural background of a particular student or group of students who you are not very familiar.

\section{To develop culturally relevant teaching approaches to better meet the needs of that student(s).}

\section{To implement these new approaches and observe} reactions and/or effects on the students.

4. To reflect on this action research experience and plan how to continue using culturally relevant teaching with these and other students in the future.

\section{Requirements}

1. Choose a video. Choose 1 of the 5 Case Study videos to design an improvement plan to embed cultural responsiveness and increase student learning. The case studies choices are:

- "Student Voices: Rosaryville ES, Upper Marlboro, MD"

- "Student Voices: Wilson Middle School, Washington, D.C."

- "Student Voices: Lily College Preparatory Academy, Annapolis, MD"

- "Student Voices: McApple Regional Academy,

Roanoke, VA"

- "Student Voices: Georgetown ES, Georgetown, DE"

Begin this project by thinking about the students in the video. Consider the group of students in the classroom whose cultural background is significantly different from yours and about whose culture you may have little knowledge. Think about the teaching approach of the educator in the video and your concerns that he or she may not be reaching them adequately.

2. Data Collection. Think about how you can learn more about that student's home culture. Reference class discussions, textbook and articles. Collect as much information as you can about their culture and create a profile of the student/student group.

3. Action Plan. Develop a plan for how you can use the information you gathered to create a plan to improve the educator's approaches with the student(s). Include the following components: prior knowledge, learning styles/ strategies, teaching method(s), lessons/activities, parent involvement.

4. Implementation. Incorporate your culturally relevant lesson plan in this Action Plan and at least one culturally relevant activity with the students.

5. Reflection. Reflect on how the new approaches and strategies will increase the educator's self-efficacy and increase the students' performance.

6. Examples: If you have any examples of worksheets or materials you developed to use for this project, be sure to include a copy. Please include only things that you made or adapted yourself for these activities. (optional)

7. References: Provide a list of all resources used throughout the project. Be sure that you have cited (APA 7) each of these in the paper. continuum provides guidance in how to incorporate a variety of activities, from individuated to integrated, to get students to experience this dissonance and to work through it. The outcome of these activities is a broadened perspective of and for K-12 students, one that allows for intersectionality in teaching.

The review and revision of individual course syllabi within a licensure program requires a systematic approach with both a micro- and macro-level lens. The new program described here included a core course entitled, Intersectionality and Disability. It was critical to the program developers, at a macro-level, to have a course that addressed issues of intersectionality in a licensure program. However, a deeper dive into the course revealed opportunities for better addressing culturally sustaining pedagogy within the course, a real need for teacher candidates (Cruz et al., 2020; Lubin et al., 2020). The process of reviewing the course syllabus in a systematic, replicable way allowed for revisions that better address the macro-level goal of producing teacher candidates who can meet the needs of diverse learners in special education. The review occurred in a stepwise fashion: (a) reading of all syllabus sections, (b) evaluating for occurrences of critical terms, (c) categorizing topics into themes and looking for missing themes, and (d) using a conceptual framework 


\section{ABOUT THE AUTHORS}

\section{Kia R. Williams}

Kia R. Williams is an ASPIRE Ph.D. scholar via a special education doctoral leadership grant with George Mason University. Her major research interests for her Ph.D. at George Mason University are the effective implementation of interventions and assistive technology, Universal Design for Learning, and teacher preparation as it pertains to culturally responsive teaching and the intersectionality of race, culture, and education.

\section{Margaret P. Weiss}

Margaret $P$. Weiss is an associate professor in the Division of Special Education and disAbility Research in the College of Education and Human Development at George Mason University. Her research interests include effective instruction in coteaching and teacher preparation.

\section{Pamela H. Baker}

Pamela H. Baker is an associate professor and Director in the Division of Special Education and disAbility Research in the College of Education and Human Development at George Mason University. Her research interests include effective preparation for administrators of special education. for revisions (Chavez \& Longerbeam, 2016).

The outcome of the review of the Intersectionality and Disability course included revised descriptions and outcomes, new assignments and activities, and a focus on self-reflection and efficacy. It also resulted in a paradigm shift from awareness of intersectionality to the more application-oriented approach of culturally sustaining pedagogy. In an independent audit of the undergraduate program, the revised course was ranked closest to being at the transformative level (e.g., challenges traditional views and encourages new ways of thinking; Kea et al, 2021). Its revision and the independent audit begin one program's journey to incorporating a cultural strengths-based mindset throughout the undergraduate experience. Though we continue our efforts to recruit teacher candidates of color, we understand that our current candidates need to be ready to learn about their students and incorporate this mindset into their instruction.

\section{Limitations}

There are limitations to the process reported. First, this article describes the review and revision of one course about diversity and intersectionality. The goal is to have this course create an intentional catalyst for a teacher candidate's journey and the ideas started here are to be woven throughout additional coursework. It is important to note that the revisions are predominantly conceptualized with the individual student's characteristics in mind rather than any particular group's characteristics. Second, it bears noting that the changes to the syllabus and assignments have not been field tested for efficacy yet. Third, the process was guided by research evidence and best practice but did not follow a validated, systematic review process. Though review processes exist (e.g., Booker \& Campbell-Whatley,

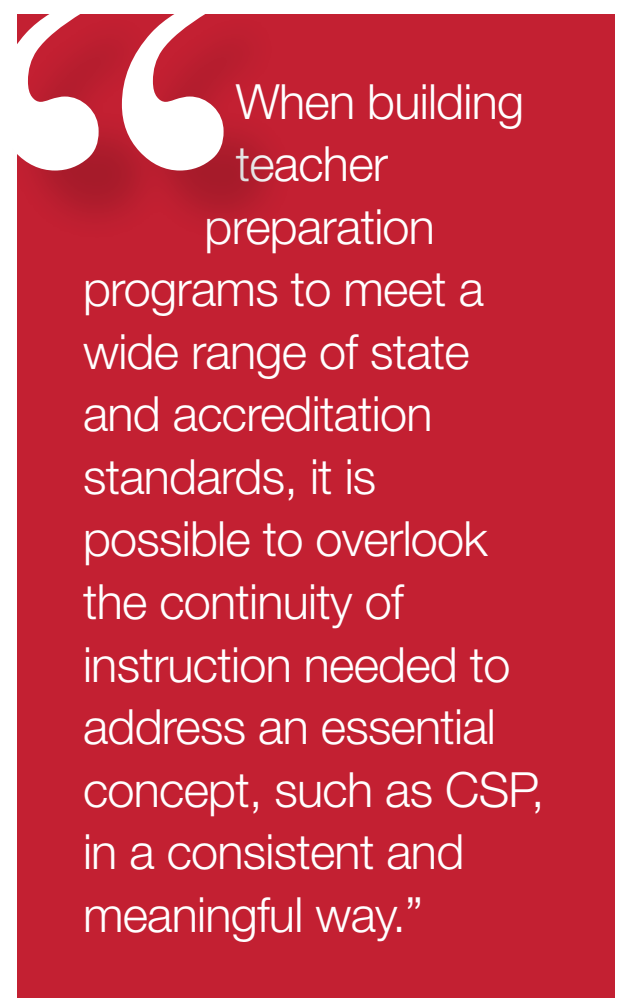

2015), they were not at the granular level that was needed so the authors had to adapt. Finally, this review was conducted by a small team led by the first author. Future reviews might include a larger group of faculty and other stakeholders in order to incorporate a wider range of perspectives into all undergraduate special education coursework. Future reviews might also examine the scaffolding of intersectionality in teaching across courses to address the complexity of using an understanding of the individual to build integrated learning experiences respectful of both the commonalities and differences among groups of students. However, given these limitations, the review and recommendations for this course have fueled the conversation within one preparation program about how to best prepare teacher candidates for the students they will serve. Future research will attempt to validate and formalize the process of review and revision in order to expand activities to all courses in the undergraduate program. 


\section{Implications for Teacher Education Programs}

Billingsley et al. (2019) remind us that all teachers need an opportunity to acquire skills for meeting the complex needs of their students. King and Butler (2015) mirror this perspective by pointing out that preparation programs cannot trust that teacher candidates will inherently pick up best practices, but that they must be taught the importance of the role of culture in a student's learning experience. Therefore, it is clear that preparation of teachers for today's schools must include intentional and explicit instruction related to CSP that extends beyond recognition into application of evidence-based practices that support a welcoming and effective learning environment for all students (Pang et al., 2021).

When building teacher preparation programs to meet a wide range of state and accreditation standards, it is possible to overlook the continuity of instruction needed to address an essential concept, such as CSP, in a consistent and meaningful way. For example, embedding course objectives that reflect expectations such as those of the Council for Exceptional Children's Initial Preparation Standards (CEC, 2021) is the foundational starting point for what should be covered. Circling back for a systematic review of courses (e.g., individual courses as well as the integration and advancement of concepts across courses) can provide programs with an opportunity for continuous improvement focused on preparing front-line special educators who are well equipped to lead learning in context with the diverse and ever-evolving needs of their students.

\section{References}

American Sociological Association. (n.d.) Culture. Retrieved from https://www.asanet. org/topics/culture
Annamma, S. A., Connor, D., \& Ferri, B. (20123). Dis/ability critical race studies (DisCrit): Theorizing at the intersections of race and dis/ability. Race, Ethnicity, and Education, 16(1), 1-31. https://doi.org/10.1 080/13613324.2012.730511

Billingsley, B. S., Bettini, E. A., \& Williams, T. O. (2019). Teacher racial/ethnic diversity: Distribution of special and general educators of color across schools. Remedial and Special Education, 40(4), 199-212. https:// doi.org/10.1177\%2F0741932517733047

Booker, K. \& Campbell-Whatley, G. D. (2015). A study of multicultural course change: An analysis of syllabi and classroom dynamics. Journal of Research in Education, 25(1), 20-31.

Boveda, M., \& Aronson, B. A. (2019). Special education preservice teachers, intersectional diversity, and the privileging of emerging professional identities. Remedial and Special Education, 40(4), 248-260. https://doi. org/10.1177\%2F0741932519838621

Chavez, A. F., \& Longerbeam, S. D. (2016). Teaching across cultural strengths: A guide to balancing integrated and individuated cultural frameworks in college teaching. Stylus.

Collaboration for Effective Educator Development, Accountability, and Reform Center (CEEDAR). (2019). Roadmap for Educator Preparation Reform framework. https:// ceedar.education.ufl.edu/roadmap/

Collier, M., Kingsley, K. V., Ovitt, B., Lin, Y.L., \& Benavidez, J. R. (2017). Fostering collaboration with families of children with disabilities: Online professional development for K-12 teachers. The Teacher Educator, 52(2), 138-154. https://doi.org/10 $.1080 / 08878730.2016 .1273421$

Council for Exceptional Children. (2021). Initial Preparation Standards. https://exceptionalchildren.org/standards/initial-special-education-preparation-standards.

Cruz, R., Manchanda, S., Firestone, A., \& Rodl, J. E. (2020). An examination of teachers' culturally responsive teaching self-efficacy. Teacher Education and Special Education, 43(3), 197-214. https://doi. org $/ 10.1177 / 0888406419875194$

Gay, G. (2002). Preparing for culturally responsive teaching. Journal of Teacher Education, 53(2), 106-116. https://doi. org/10.1177/0022487102053002003

Haynes, C., Joseph, N. M., Patton, L. D., Stewart, S., \& Allen, E. L. (2020). Toward an understanding of intersectionality methodology: A 30-year literature synthesis of Black women's experiences in higher education. Review of Educational Research, 90(6), 751-787. https://doi. org/10.3102\%2F0034654320946822

Kea, C., Sirgany, L., \& Young, F. (2021). Special education program course syllabi review. Author.

Kelly, L. B., Wakefield, W., Caires-Hurley,
J., Kganetso, L. W., Moses, L., \& Baca, E. (2021). What is culturally informed literacy instruction? A review of research in P-5 contexts. Journal of Literacy Research, 53(1), 75-99. https://doi. org $/ 10.1177 \% 2 F 1086296$ X20986602

King, E., \& Butler, B. R. (2015). Who cares about diversity? A preliminary investigation of diversity exposure in teacher preparation programs. Multicultural Perspective, 17(1), 46-52.

Kolb, A. Y., \& Kolb, D. A. (2009). The learning way: Meta-cognitive aspects of experiential learning. Simulation and Gaming, 40, $297-$ 327. https://doi.org/10.1080/15210960.201 $\underline{5.994436}$

Ladson-Billings, G. "But That's Just Good Teaching! The Case for Culturally Relevant Pedagogy," Op. cit., Theory into Practice, 34(3), 160-163. https://doi. org $/ 10.1080 / 00405849509543675$

Linan-Thompson, S., Lara-Martinez, J. A., \& Cavazos, L. O. (2018). Exploring the intersection of evidence-based practices and culturally and linguistically responsive practices. Intervention in School and Clinic, 54(1), 6-13. https://doi. org/10.1177/1053451218762574

Lubin, J., Vaz, P., \& Scott, R. (2020). Perceptions of educators on effective culturally and linguistically responsive (CLR) practices. Multicultural Education 27(34), 33-39.

National Center for Education Statistics. (2020). How many students will attend school in the fall? https://nces.ed.gov/fastfacts/display.asp? $\mathrm{id}=372 \#$ PK12 enrollment

National Center for Education Statistics. (2021). Students with disabilities. https://nces. ed.gov/programs/coe/indicator/cgg

Office of Institutional Assessment. (2021). Citation withheld to protect anonymity.

Pang, V. (2018). Diversity and equity in the classroom. Cengage Learning.

Pang, V. O., Alvarado, J. L., Preciado, J. R., \& Schleicher, A. R. (2021). Culturally relevant education: Think local within a holistic orientation. Multicultural Perspectives, 23(1), 3-16. https://doi.org/10.1080/152109 60.2021 .1877546

Paris, D. (2012). Culturally sustaining pedagogy: A needed change in stance, terminology, and practice. Educational Researcher, 41, 93-97. https://doi. org/10.3102\%2F0013189X12441244

Siwatu, K. (2007). Preservice teachers' culturally responsive teaching self-efficacy and outcome expectancy beliefs. Teaching and Teacher Education, 23(7), 1086-1101. https://doi.org/10.1016/j.tate.2006.07.011

Taylor, D. C. M., \& Hamdy, H. (2013). Adult learning theories: Implication for learning and teaching in medical education: AMEE Guide No. 83. Medical Teacher, 35(11), 1561-1572. https://doi.org/10.3109/014215 9X.2013.828153 